\title{
Escola de Belas Artes da Universidade Federal do Rio de Janeiro - Criação de website institucional
}

\section{School of Fine Arts at the Federal University of Rio de Janeiro - Institutional website creation}

\author{
Ana Karla Freire de Oliveira, Universidade Federal do Rio de Janeiro - UFRJ \\ anakarla@eba.ufrj.br
}

\author{
Hugo Borges Backx, Universidade Federal do Rio de Janeiro - UFRJ \\ hbackx@eba.ufrj.br
}

\author{
Madalena Ribeiro Grimaldi, Universidade Federal do Rio de Janeiro - UFRJ \\ mgrimaldi@eba.ufrj.br
}

\begin{abstract}
Resumo
Este artigo descreve o planejamento e implementação do website de comunicação institucional da Escola de Belas Artes da Universidade Federal do Rio de Janeiro. Esta iniciativa foi uma das ações comemorativas dos 200 anos da Instituição, pioneira no ensino das Artes na América Latina. O trabalho ocorreu de forma transdisciplinar, agregando conhecimentos de Design, Informática e Artes. Na definição do projeto gráfico buscou-se um layout que possibilitasse a navegação e pesquisa mais acessíveis e simplificadas, e em consonância com as áreas de conhecimento existentes na Escola: Artes e Design. Para melhor contextualização apresenta-se um breve histórico da Instituição, a arquitetura de informação adotada para o website, seu layout e funcionamento. As ações foram pensadas para dar melhor visibilidade e funcionalidade a complexa estrutura que compõe a Unidade, com seus 13 cursos de Graduação, dois Programas de Pós-Graduação e duas Especializações.
\end{abstract}

Palavras-chave: Escola de Belas Artes, Design da Informação, Site Institucional e Design Gráfico

\begin{abstract}
This paper describes the planning and implementation of the website of the institutional communications of the School of Fine Arts at the Federal University of Rio de Janeiro. This initiative is another of the activities celebrating the School's 200th anniversary, a pioneer in Latin America for the teaching of Arts. The work took place in a multidisciplinary way, gathering knowledge from the areas of Design, Informatics, and Arts. In the graphic project definition, we sought a layout that would make navigation and search easier, accessible, simplified, and also aligned with the existing knowledge areas at the School: Arts and Design. To better clarification, the paper presents a brief history of the Institution, and then it exposes and outlines the information architecture adopted for the website and, finally, describes its layout and operation. Those actions gave greater visibility and functionality to the complex structure that makes up the School, with 13 undergraduate, two graduate, and two specialization courses.
\end{abstract}

Keywords: School of Fine Arts, Information Design, Institutional Website and Graphic design

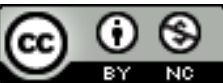




\section{A Escola de Belas Artes da Universidade Federal do Rio de Janeiro}

A atual Escola de Belas Artes foi inicialmente criada com o nome de Escola Real de Ciências, Artes e Ofícios, por meio do Decreto Real de D. João VI, em 12 de agosto de 1816, com a finalidade de promover e difundir o ensino de conhecimentos considerados como indispensáveis para a comodidade e civilização dos povos. Em 1826, passa a ser denominada de Academia Imperial de Belas Artes. Depois da República, em 1890, recebe o nome de Escola Nacional de Belas Artes, e em 1965, Escola de Belas Artes (EBA). Incorporada em 1937, à Universidade do Brasil, hoje conhecida como Universidade Federal do Rio de Janeiro (UFRJ) foi transferida para o campus do Fundão, em 1974/75, local onde se encontra até hoje.

Desde então, a Escola vem marcando sua presença em diversas áreas de conhecimento, tais como arte, design, tecnologia e cultura, em ações de caráter interdisciplinar e interdepartamental. Com figuras marcantes no contexto nacional e internacional formados na EBA, importantes para o nosso cenário cultural e acadêmico, tais como Cândido Portinari, Lúcio Costa, Oscar Niemeyer, Eliseu Visconti, Oswald Goeldi, Adir Botelho, Rui de Oliveira, Wladimir Machado, Felipe Barbosa, entre outros.

A EBA, como é chamada, representa uma instituição bicentenária com significativa produção nacional e internacional nos campos das artes e do design. Mescla sua tradição e qualidade no ensino com a tecnologia e inovação do mundo contemporâneo como missão importante na formação de profissionais diversos, assim descrito pelo ex-Diretor Professor Carlos Terra (20102018):

Sua herança cultural é transmitida a cada geração de estudantes que se formam e trilham caminhos próprios como profissionais capazes de continuar a trajetória da construção da arte brasileira. Nesses 200 anos a EBA viu surgir mestres e artistas, pensadores críticos, historiadores da arte, designers, restauradores, paisagistas, cenógrafos, escultores, pintores, gravuristas, artistas de todas as formas e poéticas e professores, que imprimiram em seus alunos a qualidade de ensino até hora reconhecida. (TERRA, 2016, p.7)

A estrutura curricular da Escola muito se modificou ao longo dos seus 204 anos de história. Agregando atualmente treze cursos de graduação: Artes Cênicas - Cenografia; Artes Cênicas Indumentária; Artes Visuais - Escultura; Comunicação Visual Design; Conservação e Restauração; Desenho Industrial - Projeto de Produto; Design de Interior; Gravura; História da Arte; Licenciatura - Artes Plásticas; Licenciatura - Desenho; Paisagismo e Pintura. Possui dois programas de pós-graduação Strictu sensu: Programa de Pós-Graduação em Artes Visuais PPGAV e Programa de Pós-Graduação em Design - PPGD, além de duas especializações Lato sensu: Especialização em Técnicas de Representação Gráfica - TRG e Especialização em Paisagem, Arte e Cultura Paisagística - PACP.

Nesse universo acadêmico, a EBA tem hoje regularmente matriculados cerca de 2700 estudantes, com pluralidade de saberes em diferentes campos de conhecimento coexistindo de forma harmoniosa e construtiva.

Diante das modificações ocorridas na Escola nas últimas décadas e a incorporação de abordagens e técnicas inovadoras de arte contemporânea havia uma demanda premente de 
reformular o website da Escola, buscando uma interface amigável, funcional e de acordo com as atividades acadêmicas e administrativas desenvolvidas na Unidade. Considera-se, neste artigo, como conceito de interface, o modo pelo qual o usuário consegue, usando um computador, interagir com um programa ou com um sistema operacional. Para melhor compreensão e delimitação dos termos 'website e interação humano-computador', seguem alguns conceitos delineadores:

Website é uma palavra que resulta da justaposição das palavras inglesas web (rede) e site (sítio, lugar). No contexto das comunicações eletrônicas, website e site possuem o mesmo significado e são utilizadas para fazer referência a uma página ou a um agrupamento de páginas relacionadas entre si, acessíveis na internet através de um determinado endereço. (Site Significados. www.significados.com.br, 2020)

\begin{abstract}
A interação humano-computador (IHC) se beneficia de conhecimentos e métodos de outras áreas fora da computação para conhecer melhor os fenômenos envolvidos no uso de sistemas computacionais interativos. Áreas como Psicologia, Sociologia e Antropologia contribuem para aquisição de conhecimento sobre cultura e o discurso dos usuários e sobre seus comportamentos no ambiente onde realizam suas atividades, sejam elas individuais ou em grupo. A definição de interface com usuário faz uso de conhecimentos e técnicas de áreas como: Design, Ergonomia, Linguística e Semiótica. (BARBOSA \& SILVA, 2010, p.12)
\end{abstract}

Cabe destacar que, em se tratando de comunicação em mídia, a internet é atualmente um dos meios potencialmente viáveis e eficientes para se propagar informação, sendo considerada uma ferramenta extremamente útil para o meio acadêmico e profissional. E de acordo com DOMINGUES (1997), vivemos em um tempo em que nada acontece fora do universo tecnológico e a cada momento nos vemos diante da interação homem-máquina.

\title{
Repensando o website da Escola de Belas Artes
}

O primeiro projeto de website para a EBA foi iniciado nos anos 2000 e apresentava uma interface um tanto rígida que não permitia grandes variações de conteúdo e imagens no layout. No final de 2009 foi reformulado com a preocupação de melhorar a comunicação com o público externo, professores, estudantes e técnicos. Tinha um caráter de Portal Acadêmico com dados sobre os departamentos, cursos e informações administrativas. A plataforma utilizada foi o sistema open source de gestão de conteúdos para web, conhecido como Joomla, um sistema livre desenvolvido em PHP e com base de dados MySQL, executado em um servidor interpretador.

Esta segunda versão do website foi desenvolvida pelo Núcleo de Computação Eletrônica (NCE) da UFRJ, obedecendo uma estrutura de informação predefinida com recursos básicos de fácil manutenção e administração via web. Tal padrão, permitia uma separação entre layout, programação e conteúdo e foi implementado para diferentes Unidades da UFRJ. Embora com algumas melhorias, a versão utilizada carecia de ser revista, principalmente em relação a uma navegação mais objetiva e rápida, bem como uma estética mais apropriada à uma Escola de Artes e Design. 
No ano de 2015, foi realizado um concurso para a nova identidade visual da EBA (Figura 1), no qual a proposta vencedora foi a da aluna Mayara Lista, do curso de graduação em Comunicação Visual Design. A Escola adquire assim uma identidade visual mais contemporânea e funcional.

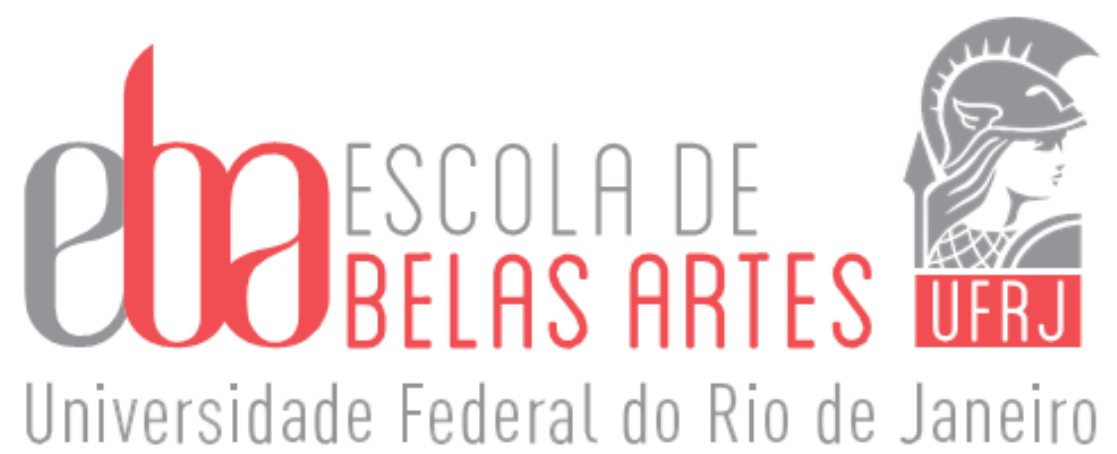

Figura 1 - Nova identidade visual da Escola de Belas Artes UFRJ no ano de 2015.

No desdobramento desse trabalho foi criado um Manual de Identidade Visual (MIV), com definição das normas de uso. Ele propunha as 'assinaturas' dos departamentos e cursos e de todo o material gráfico a ser empregado na EBA, como os cartões institucionais e certificado (Figura 2). Desta forma, com novas cores e tipografia mais moderna, tornou-se imperativa a necessidade de uma reformulação total no layout do website. $\mathrm{O}$ ato de repensar essa estrutura foi um convite relacionado ao universo da comunicação visual. Neste sentido o design gráfico se tornou um elemento fundamental a ser considerado, pois auxilia na clareza e rapidez da transmissão de informações ao usuário.

A comunicação visual apresenta vantagens relevantes para auxiliar no processamento da mensagem, ao compilar os dados e evitar o excesso de informação, o qual permite a agilidade ao longo da transmissão da informação até o receptor. Essa otimização pode ser feita com o uso de recursos criativos e elementos visuais que tornem a informação mais atrativa, e, consequentemente, intuitiva e de fácil associação. (ARAÚJO, 2017, p.29)
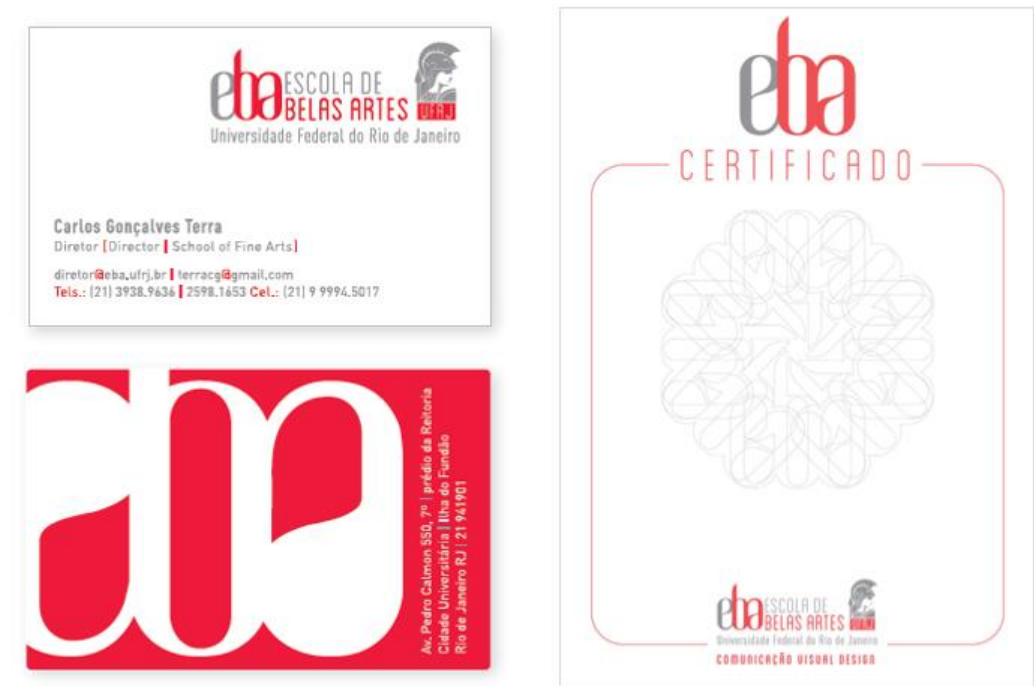

Figura 2 - Cartão de visita institucional (frente e verso) e certificado. 
Além da questão estética, um outro ponto que foi amplamente discutido no processo de reformulação é que um portal acadêmico, via Web, deve permitir um acesso e entendimento mais adequado das atividades desenvolvidas, vejamos:

\begin{abstract}
A informação tem assumido um papel de grande relevância no século XXI. Seu acesso tornase essencial, seja para busca por conhecimento ou para garantia dos direitos e cidadania. Sua difusão é caracterizada pela diversidade de fontes e canais, e a Internet, em específico a World Wide Web (WWW), tem sido cúmplice na constituição desse cenário. Websites, blogs, redes sociais, comunicadores instantâneos e sistemas de busca online, entre outras ferramentas, estão intrínsecas no dia a dia de grande parte da sociedade e tem a função de auxiliar no atendimento das demandas informacionais de modo democrático. (SILVA, 2017, p.21).
\end{abstract}

Assim, no ano de 2018, um grupo de professores do curso de Desenho Industrial e do Departamento de Técnicas e Representação começou a repensar as características visuais e a estruturação informacional para o novo website. A proposta se organizou a partir de alguns requisitos importantes que precisavam ser considerados, tais como: atualização e relevância do conteúdo; páginas rápidas e objetivas; ser responsivo; disponibilizar serviços on-line; possuir visual limpo com imagens e assuntos necessários aos usuários e, por fim, apresentar um layout mais contemporâneo. Como site responsivo, apresenta-se uma explanação a respeito:

Site ou layout responsivo, ou também conhecido como site flexível é quando o site automaticamente se encaixa no dispositivo do usuário ( $\mathrm{PC}$, celular, tablet, etc). Um site responsivo muda a sua aparência e disposição com base no tamanho da tela em que o site é exibido. Então, se o usuário tem uma tela pequena, os elementos se reorganizam para lhe mostrar as coisas principais em primeiro lugar. (Site Responsivo. www.comersite.com.br, 2020).

O trabalho iniciou-se pela elaboração do seu briefing (normas do manual de identidade visual, definição das informações a serem apresentadas, organização de documentos em pastas, criação de banco de imagens, e propostas de layout dinâmicas e contemporâneas) e posterior montagem prévia em uma plataforma digital acessível para observação do seu funcionamento.

\title{
Estrutura de navegação do novo website da EBA
}

A navegação do website abordada neste artigo pontua o projeto gráfico, envolvendo questões estéticas e comunicativas, sem expor a estrutura tecnológica e computacional utilizada.

Para iniciar a concepção visual foram realizadas pesquisas sobre sites de escolas de arte e design no Brasil e no exterior. Nesta análise de similares foram observados dados como a arquitetura de informações, layouts, estrutura de navegação, acessibilidade, entre outros fatores considerados importantes para compreensão da imagem institucional.

Após as primeiras análises, ficou evidente que seria necessário a criação de um banco de imagens relativos às atividades executadas no âmbito dos cursos. Esta coleta permitiria uma apresentação visual mais de acordo com o universo da Escola, capturando representações reais e poéticas sobre 
o fazer das artes e do design.

Já o conteúdo dos textos do site existente foi totalmente revisto e separado em categorias com teores institucionais, acadêmicos, informacionais, documentais e administrativos, com o propósito de torná-lo atual e objetivo. Um norteador adotado foi a preocupação em indicar de forma mais utilitária e clara onde obter as informações sobre a EBA. Esse era um ponto de reiteradas reclamações dos usuários internos e externos que relatavam dificuldades em encontrar os dados que necessitavam.

Como ferramenta digital inicial para a montagem prévia do website foi utilizada a plataforma Wix.com, pelo fato de a mesma possuir uma interface acessível, intuitiva e interativa. Todas as proposições de conteúdo e layout foram configuradas nesta plataforma, visando mais agilidade no processo de criação e decisão do conteúdo, layout e navegação a serem adotados. Posteriormente, após inúmeras discussões e aprimoramentos, a proposta final aceita foi transmutada, por questões técnicas, para a plataforma WordPress.com, por ser compatível com o servidor da UFRJ. Essa transmutação se deu sem perda de conteúdo e estética, por meio do trabalho de um bolsista do curso de Ciência da Computação, do Instituto de Matemática, da Universidade Federal do Rio de Janeiro, configurando-se desta forma em um trabalho transdisciplinar.

Como existiam diferentes tipos de conteúdo a serem abordados no website da EBA, foi decidida a subdivisão do menu superior em dez seções, assim dispostas:

1. Homepage: Página principal com a identidade visual da EBA, quadro de avisos e opção direta para os cursos de graduação, pós-graduação e especializações;

2. EBA: Com cinco subseções (Institucional; Direção; Relações Internacionais; Corpo Funcional; Organograma). Destas subseções, somente a aba Direção tem outras subcategorias a serem acessadas (Direção Adjunta de Pós-Graduação; Direção Adjunta de Graduação; Direção Adjunta de Extensão e Direção Adjunta de Cultura);

3. Graduação: Com dez subseções (Seção de Ensino; Cursos e Disciplinas; Departamentos e Coordenações; Oficinas e Ateliês; Laboratórios; Grade Horária; Calendário Acadêmico; COAA; NDE; Processos Acadêmicos);

4. Pós-Graduação e Pesquisa: Com cinco subseções (PPGAV; PPGD; Especialização TRG; Especialização PACP; Grupos de Pesquisa);

5. Extensão e Cultura: Com duas subseções (Extensão e Cultura);

6. Acervo: Com cinco subseções (Museu D. João VI; Biblioteca de Obras Raras; Arquivo Histórico; Biblioteca Alfredo Galvão; Publicações (com três subseções: Edições EBA, Arquivos, Boletim Obras Raras);

7. Direitos Autorais: Com sete subseções (Procedimentos; Pagamento; Registro com cessão; Formulário; Descrição de Obra; Buscas; Averbações). O setor de Direitos Autorais da Escola de Belas Artes foi criado em 10 de março de 1917 e, em 2019, contam com aproximadamente 75 mil registros. É regulado pela lei $n^{\circ} .9 .610$, de 19 de fevereiro de 1998. O certificado de registro autoral é uma medida de cautela, com a finalidade de declarar o direito do autor, sendo recomendável, sobretudo quanto à autoria de determinadas criações. 
8. Informações: Com quatro subseções (Direção; Editais e Concursos; Discentes; Ouvidoria). A aba Direção possui três subseções (Congregações, Moções e Notas Oficiais, Regimento). A aba Discentes possui três subseções (Manual do Estudante, Estágio, Monitoria);

9. Formulários: Com três subseções (Formulários Discentes; Formulários Docentes; Formulários Administrativos). A aba Formulários Docentes possui duas subseções (Estágio Probatório, Progressão/Promoção);

10. Contato: Página com informações para contato com a instituição (Endereço com mapa, e-mail e telefone).

Para uma melhor visualização sobre a estrutura de navegação do novo website da Escola de Belas Artes, a Figura 3 ilustra as dez seções do menu superior e suas subseções correspondentes.

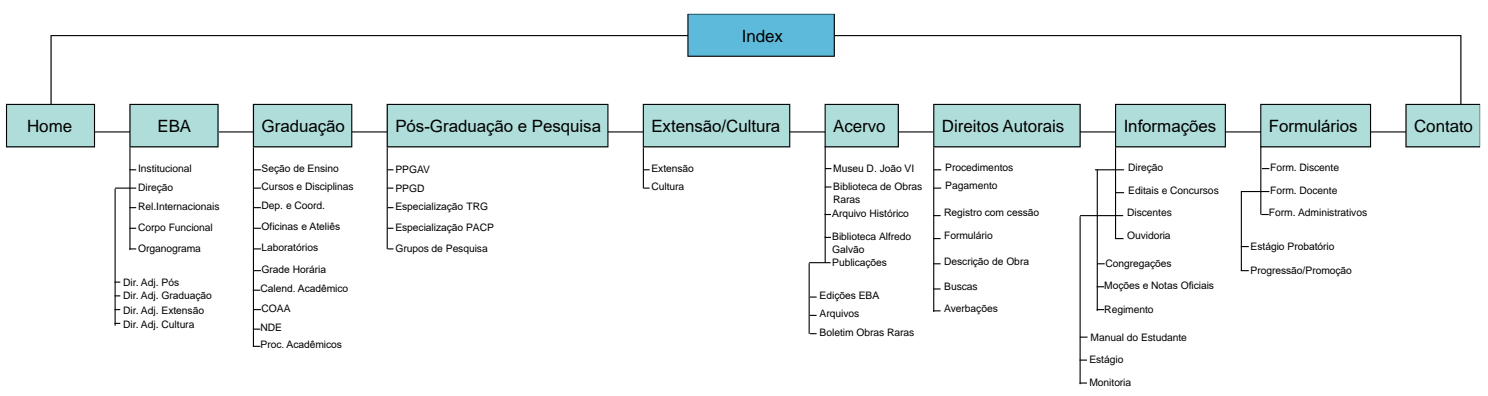

Figura 3 - Estrutura de navegação do website da EBA.

Como se observa na Figura 3, as dez seções do menu superior foram organizadas de modo a dispor todas as informações, desde seu arranjo institucional, passando por subsídios acadêmicos e culturais, o acervo com as publicações e por fim, dados administrativos. Segundo relatos de usuários internos (docentes, discentes e técnicos), a navegação apresentou significativas melhorias na busca por informações e dados.

Outro ponto levantado durante a estruturação é que as páginas eletrônicas institucionais se encontram diretamente relacionados aos serviços por elas prestados, e neste caso, o website da EBA teve por premissa atender às necessidades dos seus usuários e melhorando sua usabilidade. Neste sentido, Nielsen e Loranger destacam que:

Há dez anos a Web era algo diferente para as pessoas. Hoje ela é uma rotina, é uma ferramenta. Se for de fácil acesso, elas a utilizarão, do contrário, não. Com dez vezes mais sites e provavelmente centenas de páginas na Web, os usuários estão menos tolerantes a sites complexos. Portanto um projeto falho significa negócios perdidos. Nunca a usabilidade foi tão importante. (NIELSEN \& LORANGER, 2007, p. 396).

Nielsen (1993) também aponta que "a usabilidade é a elaboração de projetos de websites visando à qualidade, a eficiência, eficácia e satisfação do usuário, ou seja, facilidade de uso e busca das informações de que necessitam no website". (NIELSEN, 1993, citado por SILVA, 2017, p.29). 
Ainda seguindo esse raciocínio, em se tratando de ambiente web, a usabilidade pode contribuir para eliminar barreiras entre o usuário e o website e/ou sistema (SILVA, 2017).

\begin{abstract}
A usabilidade também era conhecida como Engenharia de Usabilidade, que por sua vez era composta por um conjunto de métodos e técnicas estruturadas definida como "a extensão em que um produto pode ser usado por usuários específicos para alcançar objetivos específicos como efetividade, eficácia e satisfação num contexto específico de uso. (ABNT NBR ISO 9241-11, apud SILVA, 2017, p.31).
\end{abstract}

Assim, no projeto de reformulação do website da Escola de Belas Artes levou-se em consideração a efetividade, a eficiência e a satisfação do usuário quando da utilização da plataforma digital. Oferecendo uma interface amigável aliada a uma estética minimalista com linhas e formas clássicas e conteúdo bem estruturado.

Todo processo de mudança requer uma adaptação e constante melhoria para um melhor desempenho, principalmente no que ser refere à criação de um website institucional. A verificação da usabilidade se faz necessária tanto no planejamento de um website quanto na implementação do mesmo (pós-produção), visando a sua constante melhoria. Portanto, a ideia dos autores do site é que, após o período de adequação e a partir de um feedback de subsídios dos usuários internos (docentes, discentes e funcionários), sejam realizadas mudanças no sentido de melhorar periodicamente o processo de navegação.

\title{
Projeto gráfico adotado para o website
}

A partir do Manual de Identidade Visual (MIV) adotado para a Escola de Belas Artes, no ano de 2015, foi possível traçar o aspecto estético, as diretrizes formais e conceitos a serem considerados na criação do novo website. As cores, tipografia, imagens, layout foram trabalhados em consonância visual com a identidade reformulada e levando em consideração diferentes tipos de plataformas digitais. Neste sentido, Nielsen observa que:

\footnotetext{
Uma questão de extrema importância é a compatibilidade do projeto gráfico com diferentes tipos de plataformas, navegadores e configurações de vídeo que o computador do usuário pode estar utilizando. Caso não seja levada a sério esta questão, corre-se o risco de o website perder eficiência ou se tornar inacessível. (NIELSEN, 2000, citado por JÜNGE \& MERINO, 2012, p.5).
}

Para a exposição imagética da Escola, foi utilizado o banco de dados criado com situações e momentos representativos de atividades desenvolvidas no âmbito dos cursos de graduação, de pós-graduação, extensão e ações culturais. Essa coletânea se mostrou extremamente importante para dar visualidade ao site, apresentando o savoir faire da EBA de modo poético, porém, objetivo. Tal atributo não havia sido trabalhado nas versões anteriores do website e foi recebido 
com entusiasmo pelos usuários internos, segundo relatos. Esse acervo possui ao menos 400 imagens ilustrando atividades diversas realizadas na Escola, tais como aulas práticas nas oficinas e ateliês, salas de aulas, infraestrutura tanto do prédio Jorge Moreira Machado JMM (Sede da Escola de Belas Artes) quanto do paisagismo existente (por Roberto Burle Marx). As fotos também contemplam materiais utilizados nas aulas (tintas, pincéis, lápis de cor), objetos do cotidiano acadêmico, entre outros que expressassem visualmente o universo das artes e do design trabalhados na EBA. A ideia do projeto é que essa coletânea seja constantemente reformulada para ser utilizada na manutenção e atualização do website. Um ponto a destacar sobre as imagens, é que as mesmas foram selecionadas de modo que representassem a atividade manual. Remetendo assim, ao fazer com as mãos e a diferentes materiais e instrumentos que permitem relacionar o 'pensamento visual' com a habilidade de se expressar por meio do desenho.

O layout adotado para a página principal (homepage) do website primou por apresentar de forma clara e objetiva a Escola como um todo, em especial seus 13 cursos de graduação acessíveis tanto pelo menu principal quanto na galeria em quadros criada com imagens representativas e descritivas de cada um dos cursos. Em relação à homepage destacamos que:

No desenvolvimento da arquitetura da informação, uma das primeiras etapas após analisar os dados do briefing é pensar na página de abertura do site, a homepage. Ela deve mostrar ao usuário como navegar pelo site e quais assuntos, produtos ou serviços o usuário irá encontrar. Desse modo, é importante que a homepage se destaque das demais páginas do site. Isso não significa um design totalmente diferente das outras páginas, apenas que algumas informações merecem um destaque maior, como a logomarca da empresa e os objetivos do site. (ASSUMPÇÃO \& VILLEGAS, 2013, p.4)

A Figura 4 ilustra a malha gráfica pensada para a homepage (imagem à esquerda) e as páginas secundárias (imagem à direita) do website.
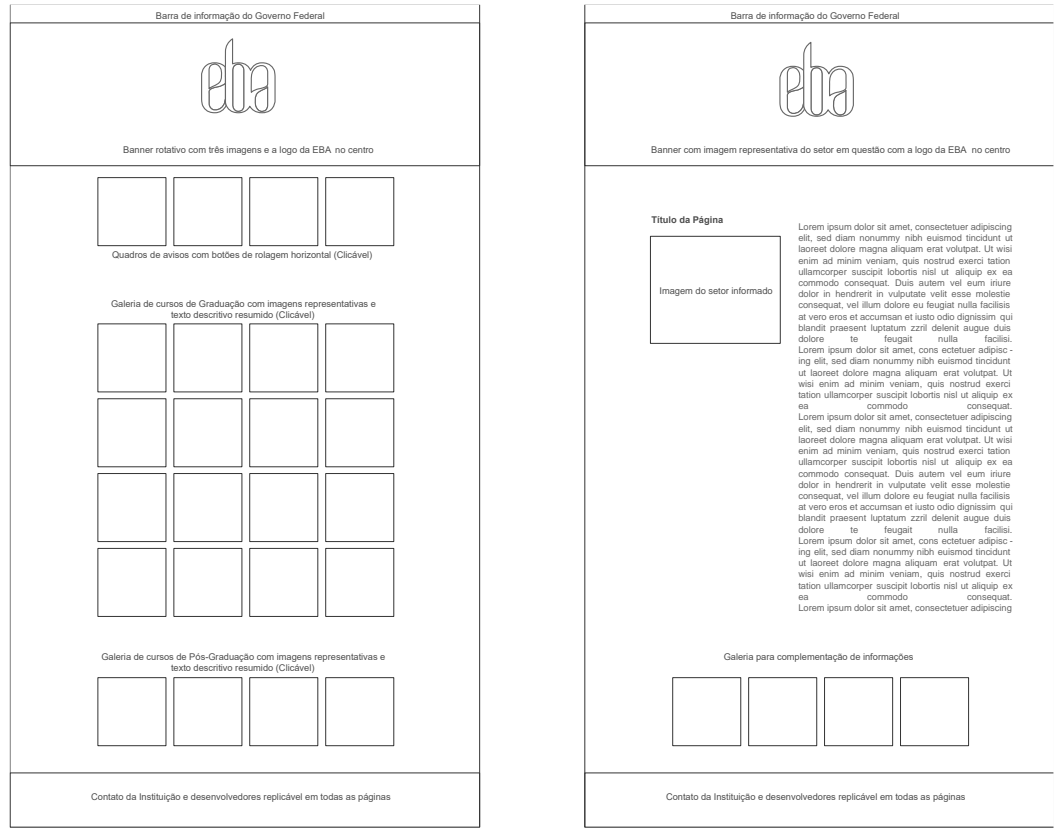

Figura 4 - Malhas gráficas da homepage e das páginas secundárias. 
Na homepage, em primeiro plano foi adotado um banner rotativo com três imagens, tendo como figura central a identidade visual da EBA (como elemento de pregnância visual) aplicado sobre as fotos. Cabe destacar que as imagens foram recortadas e que se priorizou a ideia do 'fazer com as mãos'. Em seguida, ao rolar a página para baixo, o usuário tem acesso a informes (clicando em cada um, é possível obter mais informações) de natureza acadêmica, artística, cultural, de assistência estudantil, entre outros (a Figura 5 ilustra o banner principal superior e o quadro de avisos). Esse quadro funciona como um mural rotativo, disposto em quatro módulos quadrados em linha. De acordo com o quantitativo das informações pode se ter várias linhas e sua visibilidade se dá por meio de duas setas na parte central inferior dos módulos.
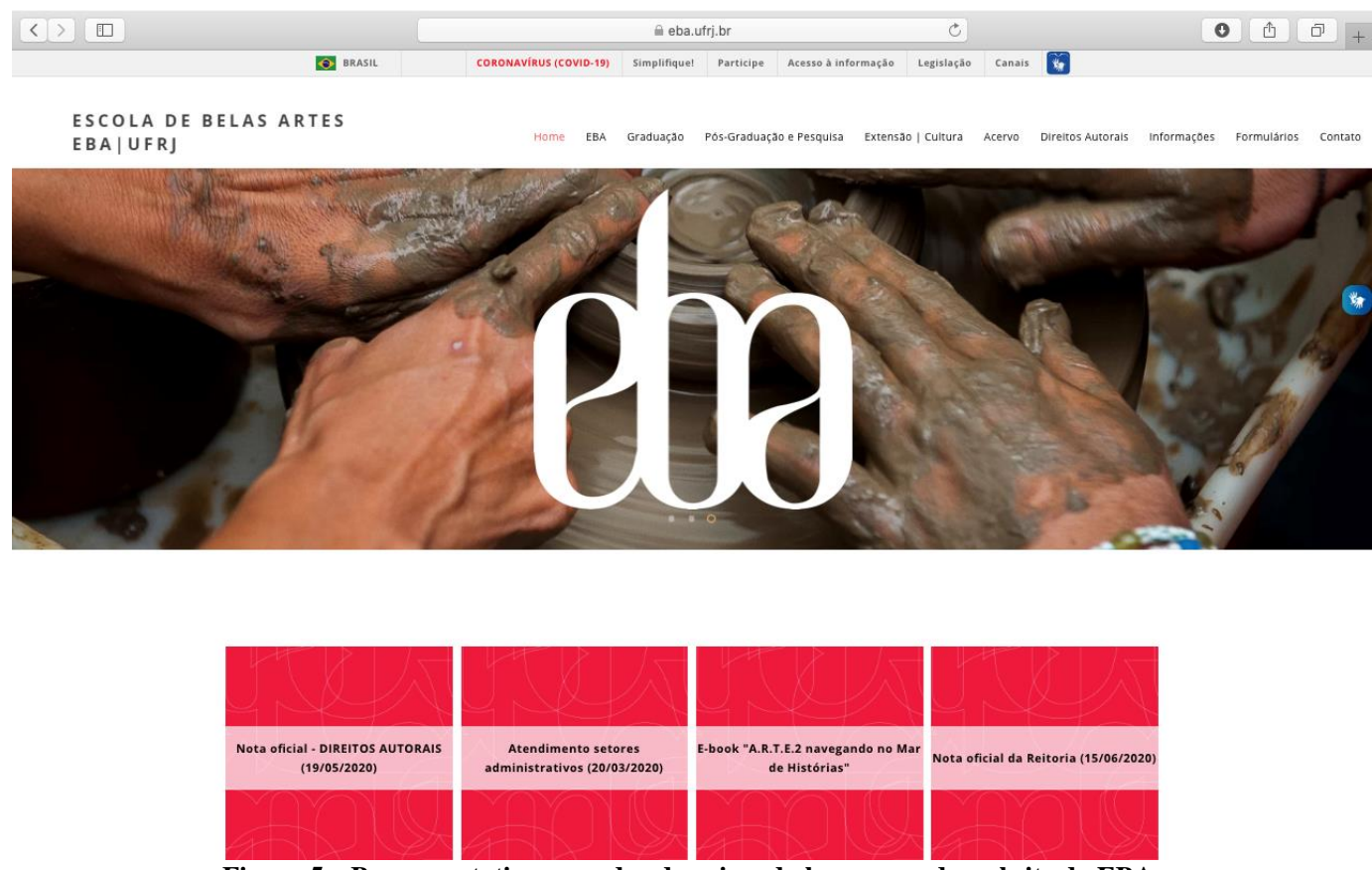

Figura 5 - Banner rotativo e quadro de avisos da homepage do website da EBA.

Em seguida, ainda na homepage, apresenta-se a galeria de quadros com os cursos de graduação oferecidos na Escola com uma breve descrição de cada um deles (imagem e texto) e, caso o usuário se interesse por saber mais, pode clicar no quadro do curso, sendo direcionado para a página corresponde (Figura 6). 


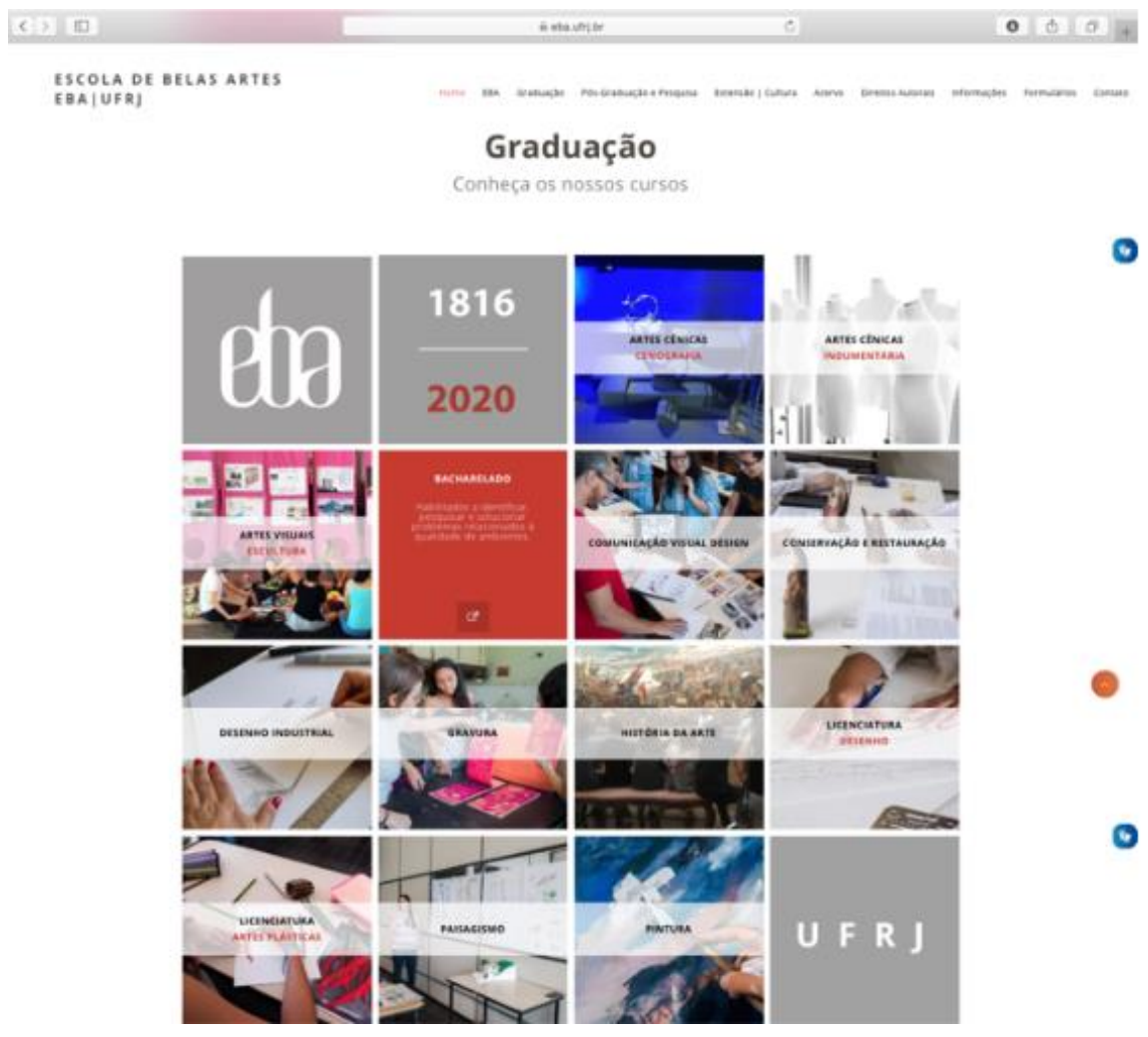

Figura 6 - Galeria de cursos de graduação na homepage do website da EBA.

Dando seguimento à navegação da homepage, o usuário se depara com a galeria de quadros (imagem e texto) dos cursos de Pós-Graduação da EBA, sendo o mesmo sistema adotado para os cursos de graduação, no qual se o usuário quiser saber mais a respeito, será direcionado para a página correspondente (Figura 7). Por fim, tem-se o rodapé da página com o contato da instituição (e-mail) e os nomes dos desenvolvedores do site.

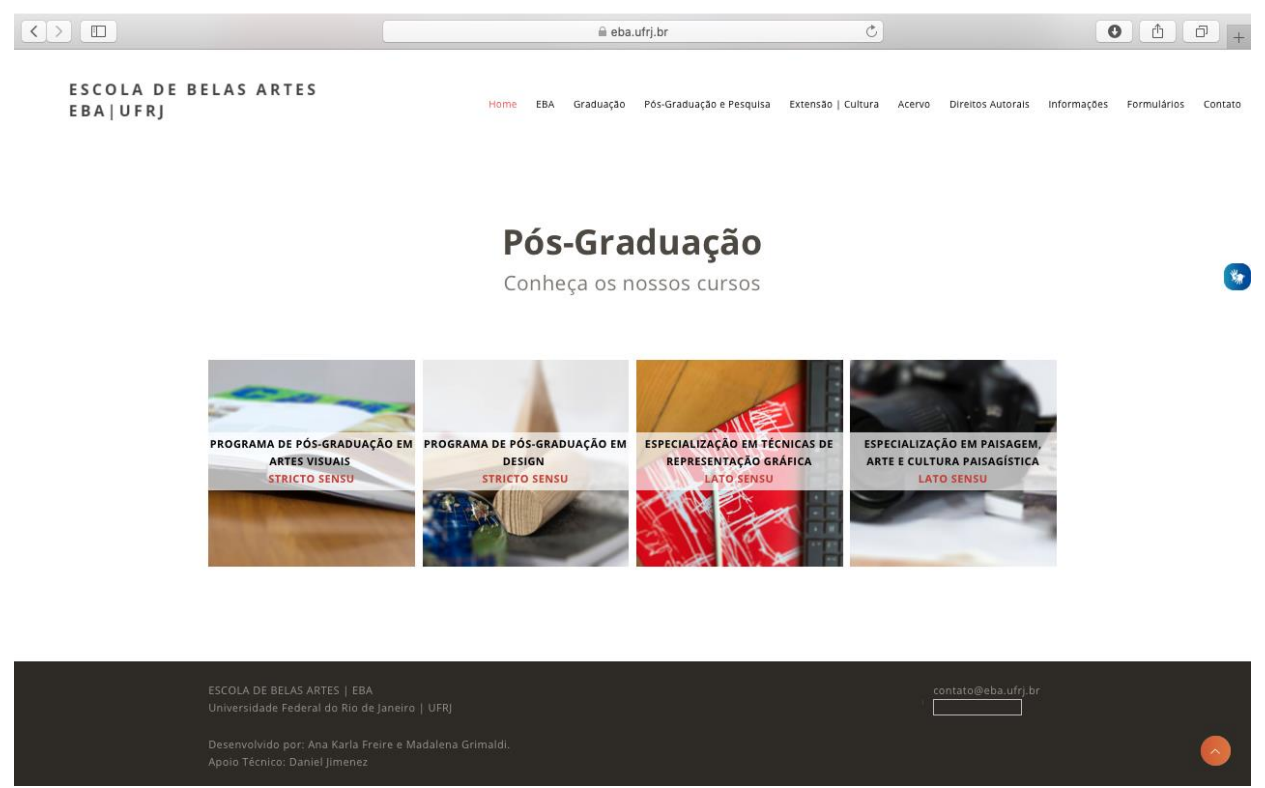

Figura 7 - Galeria de cursos de pós-graduação na homepage do website da EBA. 
A estrutura de layout adotada para as páginas secundárias (subseções do menu superior) levou em consideração a disponibilização de uma boa experiência do usuário, tanto em relação à organização dos textos e das imagens, quanto à escolha da fonte tipográfica não serifada em tom de cinza 80\% (Figura 8). Também houve a preocupação, quando possível, de correlacionar o conteúdo da seção com a imagem escolhida, como por exemplo: na aba Pós-Graduação e Pesquisa foram usadas fotos com detalhes de livros; na aba do Museu D. João VI uma escultura do acervo, e assim sucessivamente.

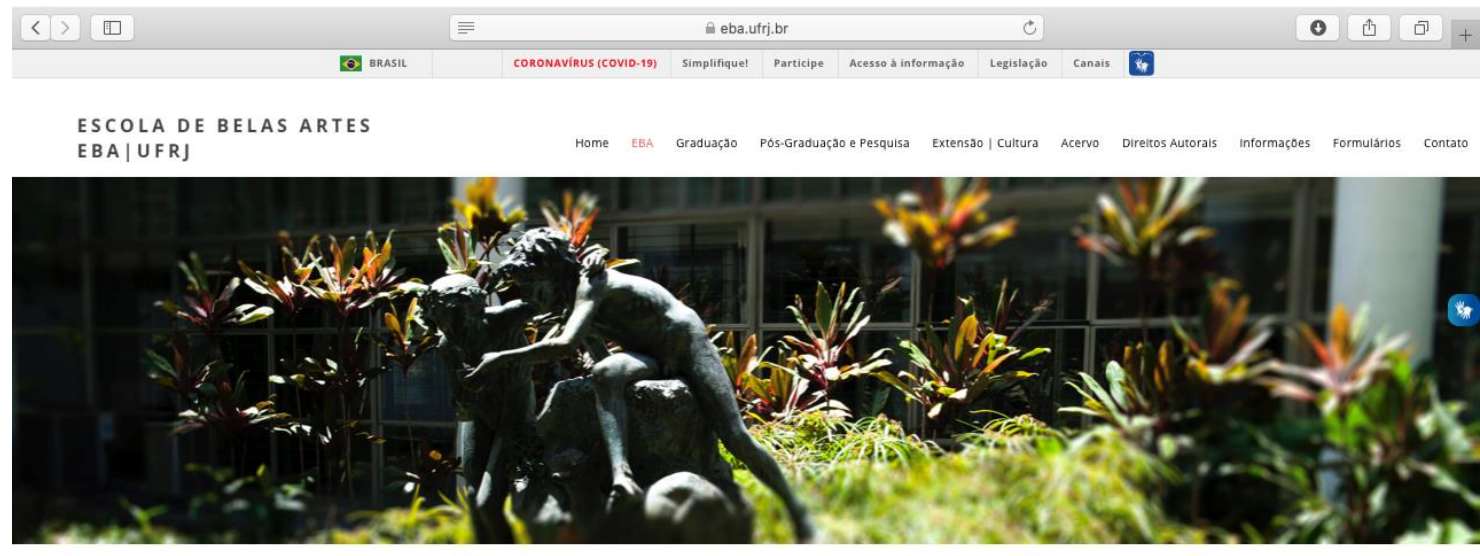

INSTITUCIONAL
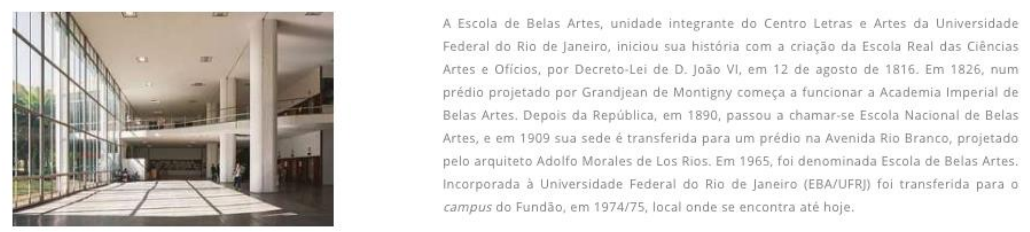

Figura 8 - Imagem ilustrando o layout adotado para as páginas secundárias do website.

A aba referente ao Acervo, merece algumas informações adicionais, por contemplar subseções de extrema relevância para a Unidade e que necessitavam de uma maior visibilidade tanto para o público interno quanto externo. Nela se encontra o Setor de Memória e Patrimônio que se subdivide no Museu D. João VI, na Biblioteca de Obras Raras e nos Arquivos Histórico. É possível coletar informações básicas sobre os três setores e ser redirecionado para páginas próprias com acesso aos respectivos acervos (coleção de artes, bibliográfica, documental e informacional) que apoiam as atividades acadêmicas e de pesquisa. A subseção da Biblioteca Alfredo Galvão, segue a mesma metodologia. Por fim, a parte de Publicações (com três subseções: Edições EBA, Arquivos, Boletim Obras Raras) apresenta a possibilidade de acesso a produções da Escola e ao periódico: Arquivos da EBA, que estão nessa versão atual da website disponibilizados on-line. Os Arquivos da EBA possuem como objetivo divulgar artigos, ensaios, entrevistas e resenhas de seus professores e pesquisadores e, registrar os dados e as principais realizações ocorridas a cada ano. Esse espírito de registro e partilha de informações foi uma das 
diretrizes pontuadas no projeto de construção do site, ou seja, disponibilizar um conjunto de documentos escritos e de imagens, que servissem para os estudos e pesquisas ligados a Arte e ao Design e da memória da Instituição (Figura 9).

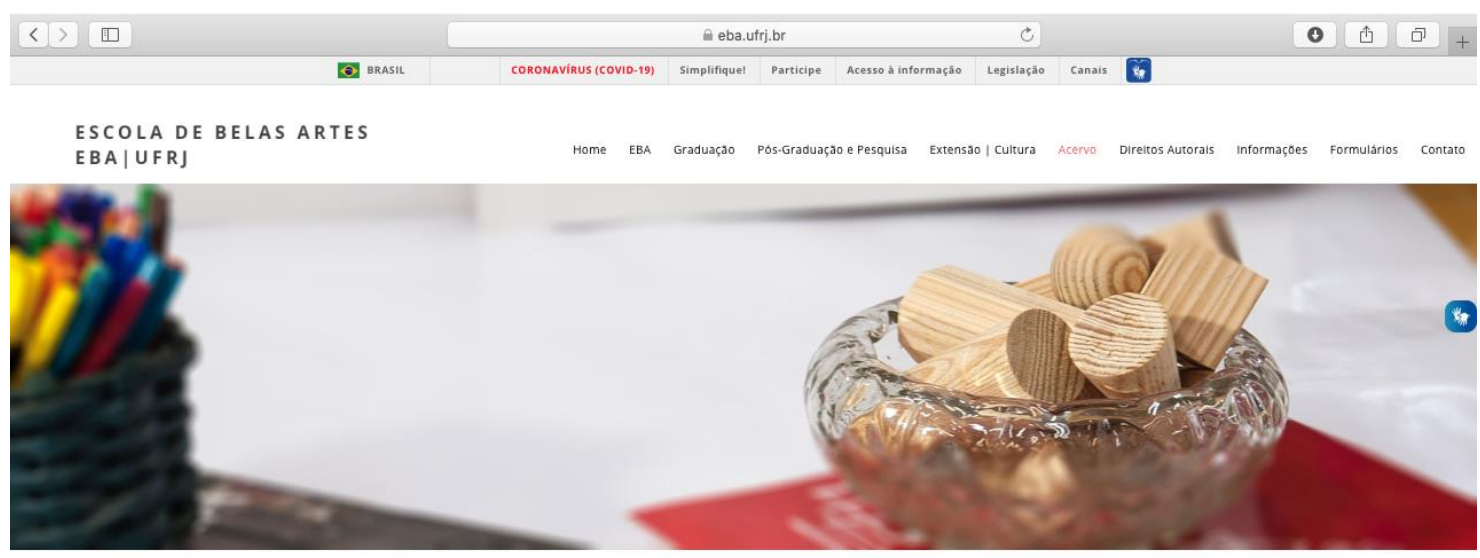

PUBLICAÇŌES ARQUIVOS

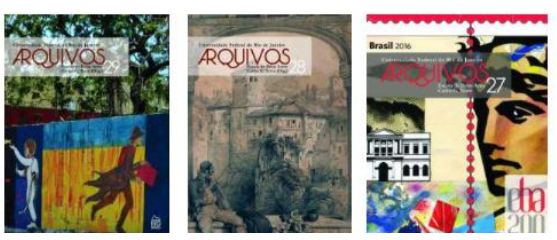

Figura 9 - Página ilustrando o layout da aba Publicações do website.

Por questões de espaço, não serão aprofundados aqui pontos relativos às demais seções criadas. Para um conhecimento mais detalhado sobre o website se faz necessário uma "visita", o que os autores convidam o leitor a fazê-lo.

A implantação do website foi direcionada para o endereço eletrônico institucional (www.eba.ufrj.br), utilizando a linguagem WordPress no servidor da UFRJ. A divulgação se deu por envio de e-mails ao público interno (docentes, discentes e técnicos administrativos) e externo (instituições diversas). As atualizações são realizadas constantemente por técnicos da Escola com conhecimento na plataforma WordPress. Como passos futuros e para atingir públicos mais diversos, o website terá mais duas versões, em língua inglesa e espanhola.

Por se tratar de uma unidade acadêmica da Universidade Federal do Rio de Janeiro, o site precisava conter informações obrigatórias na sua parte superior, acima do menu principal, com informações remetendo ao Governo Federal, dando acesso simplificado às informações.

\section{Considerações finais e desdobramentos}

Para o desenvolvimento de um site institucional é preciso um planejamento minucioso que considere como premissa fundamental as necessidades do público usuário da plataforma 
multimídia. Desta forma, o novo website criado para Escola de Belas Artes foi estruturado com o objetivo de melhorar a experiência do usuário, disponibilizando em uma estrutura gráfica organizacional (arquitetura da informação) os dados institucionais, acadêmicos, administrativos, informacionais, documentais e culturais.

A partir de uma pesquisa de avaliação dos usuários, realizada no primeiro mês após a implantação do site, chegou-se à conclusão que o mesmo melhorou sua interface e por consequência, a experiência de navegação, respeitando e mantendo a tradição da Escola no ensino, pesquisa e extensão das Artes e do Design.

O processo de criação do website se deu de forma transdisciplinar, possibilitando uma integração de conhecimentos e áreas de atuação do Design, Artes e Informática, além de integrar duas Unidades de Ensino da Universidade Federal do Rio de Janeiro, a EBA e o Instituto de Matemática, onde está inserido o Curso de Ciência da Computação. O processo criativo do website da EBA não ocorreu de forma linear, mas a partir de um método cíclico tomando o briefing como parâmetro.

A ideia é que o website seja constantemente aperfeiçoado para uma melhor experiência em multimídia, sendo este passo inicial significativo para se obter uma plataforma digital dinâmica, atual e utilitária voltada ao ensino das artes e design no país. Futuramente serão lançadas as versões em inglês e espanhol visando atingir diversos públicos.

\section{Referências}

ASSUMPÇÃO, D. J.F.; VILLEGAS, G.M.L. Processo de criação em websites: um estudo de caso do site IESAM. Dito e Feito. ISSN 1984-2376. Ano IV. Vol. 4, Nº 4. Jan-Jun. 2013. UTFPR. Campus Curitiba.

ARAÚJO, A.C.C. Comunicação visual no processo de geração de ideias: uma proposta para a técnica de criatividade creation. Dissertação de mestrado apresentada ao programa de Pós-Graduação em Engenharia de Produção da Universidade Federal do Rio Grande do Norte. 150p. 2017.

BARBOSA, S.D.J; SILVA, B.S. Interação humano-computador. Rio de Janeiro: Elsevier, 2010. Il. - (Série SBS, Sociedade Brasileira de Computação)

DOMINGUES, Diana (Org.). Arte no Século XXI: a humanização das tecnologias. São Paulo: Editora UNESP, 1997.

JÜNGE, j; MERINO, E. Design e Usabilidade: A internet como apoio para disponibilizar material didático. 2012. Repositório UFSC. Disponível em: https://repositorio.ufsc.br/handle/123456789/1843. Acesso em: 27 de julho de 2020.

NIELSEN, J. Usability Engineering. Boston - USA: Academic Press, 362 p, 1993.

; LORANGER, H. Usabilidade na web: projetando websites com qualidade. Rio de Janeiro: Elsevier, 2007.

SIGNIFICADO. Significado de website (O que é. Conceitos. Definição). Disponível em: https://www.significados.com.br/website/. Acesso em: 20 de julho de 2020. 
SILVA, S. C.L. Usabilidade em websites de arquivos nacionais. Dissertação de Mestrado. Universidade Federal de Santa Catarina. 156 p, 2017.

SITE RESPONSIVO. Disponível em: https://www.comersite.com.br/?s=site+responsivo. Acesso em: 20 de julho de 2020.

TERRA, C. Prefácio. In: LUZ, A.A. Escola de Belas Artes 1816-2016. Duzentos anos construindo a arte brasileira. Catálogo da exposição, de 10 de novembro de 2016 a 12 de fevereiro de 2017. Museu Nacional de Belas Artes, 128 p.; 2016.

\section{Sobre os autores}

\section{Ana Karla Freire de Oliveira}

Professora Associada do Curso de Design Industrial e do Programa de Pós-Graduação em Design da Escola de Belas Artes, UFRJ. Pós-Doutorado em Design, Universidade de Aveiro, Portugal. Doutora em Engenharia de Materiais, PUC Rio. Mestre em Engenharia Agrícola, UFCG. Bacharelado em Desenho Industrial, UFPB. Pesquisadora da área Design \& Materiais. ORCID: https://orcid.org/0000-0002-8426-9845

\section{Hugo Borges Backx}

Professor Adjunto do Curso de Design Industrial, Escola de Belas Artes, UFRJ. Doutor em Design PUC-Rio. Mestre em Engenharia de Produção COPPE/UFRJ. Graduado em Direito, CUAM. Bacharel em Desenho Industrial UFRJ. Advogado OAB/RJ 111472. Experiência na área de design de produto, perícia judicial em contratação de design, Propriedade Intelectual. Coordenador do Laboratório de Propriedade Intelectual - Lapi / UFRJ.

\section{Madalena Ribeiro Grimaldi}

Professora Associada do Departamento de Técnicas de Representação Gráfica e do Programa de Pós-Graduação em Design da Escola de Belas Artes, UFRJ. Pós-Doutorado em Arte e Filosofia, Plymouth University, Inglaterra. Doutora em Planejamento Urbano e Regional, UFRJ. Mestre em Arquitetura, FAU UFRJ. Bacharelado em Arquitetura, FAU UFRJ. Pesquisadora da área de Representação Projetiva. Diretora da EBA. ORCID: https://orcid.org/0000-0003-3410-2673. 